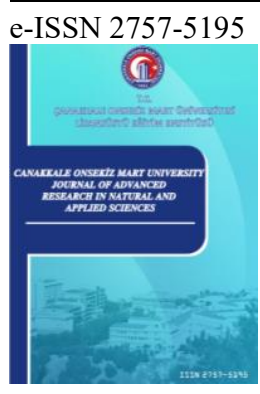

Çanakkale Onsekiz Mart University

Journal of Advanced Research in Natural and Applied Sciences

Open Access

\title{
Macar fiği (Vicia pannonica Crantz) Tohumlarının Bazı Fiziksel ve Fizyolojik Özelliklerinin Belirlenmesi Üzerine Bir Araştırma
}

\author{
Zeynep Dumanoğlu ${ }^{1 *}$, Erdal Çaçan², Kağan Kökten ${ }^{3}$ \\ ${ }^{1}$ Bingöl Üniversitesi Ziraat Fakültesi Biyosistem Mühendisliği Bölümü, Bingöl, Türkiye \\ ${ }^{2}$ Bingöl Üniversitesi Gıda, Tarım ve Hayvancılık Meslek Yüksekokulu Bitkisel ve Hayvansal Üretim Bölümü, Bingöl, Türkiye \\ ${ }^{3}$ Bingöl Üniversitesi Ziraat Fakültesi Tarla Bitkileri Bölümü, Bingöl, Türkiye \\ Makale Tarihçesi \\ Gönderim: $\quad 05.04 .2021$ \\ Kabul: $\quad 17.08 .2021$ \\ Yayım: $\quad 15.12 .2021$ \\ Araştırma Makalesi \\ Öz - Bu çalıșma, 10 adet Macar fiği çeșidine ait tohumların bazı fiziksel ve fizyolojik özelliklerin incelenmesi \\ amaciyla 2020 yılında Bingöl Üniversitesi ve Ege Üniversitesi Laboratuvarlarında yürütülmüştür. Macar fiği \\ tohumlarına ait uzunluk $(\mathrm{mm})$, genişlik $(\mathrm{mm})$, yüzey alanı $\left(\mathrm{mm}^{2}\right)$, aritmetik çap $(\mathrm{mm})$, geometrik çap (mm), \\ küresellik ve bin tane ağırlığı gibi fiziksel özellikler ile çimlenme yüzdesi, çimlenme zamanı, sürgün uzunluğu (cm) \\ ve kök uzunluğu $(\mathrm{cm})$ gibi bazı fizyolojik özellikler incelenmiștir. Macar fiği çeșitlerine ait tohumların ortalama \\ olarak uzunlukları $4.034 \mathrm{~mm}$, genişlikleri $3.780 \mathrm{~mm}$, yüzey alanları $12.459 \mathrm{~mm}^{2}$, aritmetik çapları $3.907 \mathrm{~mm}$, \\ geometrik çapları $21.427 \mathrm{~mm}$ ve küresellik değeri ise 5.158 olarak tespit edilmiş ve incelenen bu özellikler, çeşitler \\ arasında istatistiksel olarak farklılık göstermiştir. Tohumların bin dane ağırlığı ortalama $37.065 \mathrm{~g}$ olarak \\ belirlenmiştir. Çeşitler arasında Anadolu Pembesi 2002 ve Oğuz 2002 çeşitleri çimlenemedikleri için çimlenme \\ yüzdesi, çimlenme zamanı, sürgün ve kök uzunlukları hesaplanamamıștır. Geriye kalan çeşitlerin çimlenme oranları \\ \%88-99, çimlenme zamanları 1,448-1,631 gün, sürgün uzunlukları 5.613-10.227 cm ve kök uzunlukları ise 4.191- \\ $6.661 \mathrm{~cm}$ arasında tespit edilmiștir. Sonuç olarak, incelenen fiziksel özellikler açısından Anadolu Pembesi-2002 ve \\ Oğuz 2002 çeşitlerinin, incelenen fizyolojik özelliklerden çimlenme oranı açısından Kansur ve Tarm Beyazı 98, \\ çimlenme süresi açısından Sarıefe, sürgün uzunluğu açısından Akçalar ve Kansur, kök uzunluğu açısından ise \\ Akçalar çeşidinin üstün özellikler gösterdiği tespit edilmiştir.
}

Anahtar Kelimeler - Macar fiği, tohum boyutlarl, tohum özellikleri, Vicia pannonica Crantz, yem bitkisi

\section{A Research on The Determination of Physical and Phsiological Properties of Hungarian Vetch (Vicia pannonica Crantz) Seeds}

\author{
${ }^{1}$ Department of Agriculture Engineering, Faculty of Biosystem Engineering, Bingol University, Bingol, Turkey \\ ${ }^{2}$ Department of Crop and Animal Production, Vocational School of Food, Agriculture and Livestock, Bingol University, Bingol, Turkey \\ ${ }^{3}$ Department of Agriculture Engineering, Faculty of Field Crops, Bingol University,, Bingol, Turkey
}

Article History

Received: $\quad 05.04 .2021$

Accepted: $\quad 17.08 .2021$

Published: $\quad 15.12 .2021$

Research Article

\begin{abstract}
This study was carried out in order to examine some physical and physiological characteristics of seeds belonging to 10 Hungarian vetch varieties in Bingöl University and Ege University Laboratories in 2020. Physical properties of Hungarian vetch seeds such as length $(\mathrm{mm})$, width $(\mathrm{mm})$, surface area $\left(\mathrm{mm}^{2}\right)$, arithmetic diameter $(\mathrm{mm})$, geometric diameter $(\mathrm{mm})$, sphericity and thousand grain weight and some physiological characteristics such as germination percentage, germination time, shoot length $(\mathrm{cm})$ and root length $(\mathrm{cm})$ were investigated. The average length of the seeds of the Hungarian vetch varieties was $4.034 \mathrm{~mm}$, their width was $3.780 \mathrm{~mm}$, their surface area was 12.459 $\mathrm{mm}^{2}$, their arithmetic diameter was $3.907 \mathrm{~mm}$, their geometric diameter was $21.427 \mathrm{~mm}$, and the sphericity value was determined as 5.158, and these characteristics were statistically different between the varieties. Thousand grain weight of the seeds were determined to $37.065 \mathrm{~g}$ on average. Since Anadolu Pembesi 2002 and Oğuz 2002 varieties could not germinate, germination percentage, germination time, shoot and root length could not be calculated. The germination rates of the remaining varieties were found to be $88-99 \%$, germination time $1,448-1,631$ days, shoot lengths 5.613-10.227 cm and root lengths between 4.191-6.661 cm. In conclusion, it was determined that Anadolu Pembesi-2002 and Oğuz-2002 varieties showed superior properties in terms of the examined physical properties. It was determined that Kansur and Tarm Beyazı 98 in terms of germination rate, Sarıefe in terms of germination time, Akçalar and Kansur in terms of shoot length, and Akçalar variety in terms of root length.
\end{abstract}




\section{Giriş}

İklim değişimleri ve küresel 1sınma ile birlikte sürdürülebilir tarım ilkesine bağlı kalarak insanların beslenme ihtiyacını karşılamaya yönelik pek çok araştırma yapılmaktadır. Diğer yandan, tarım yapılan arazilerin giderek küçülmesi bitkisel üretim kadar hayvansal üretiminde sıkıntıya sokmaktadır. Özellikle hayvansal üretimin en önemli basamaklarından birisi olan hayvanların beslenme ihtiyaçlarını çayır ve meralardan karşılanması gün geçtikçe zorlaşmaktadır. TÜİK (2019) verilerine göre toplam arazi miktarının 14.6 ha kısmını çayır ve mera arazileri oluşturmaktadır. Buralardan giderilemeyen beslenme ihtiyacı yem bitkilerinin üretimi ile karşılanmaya çalışılmaktadır. Bu amaçla kullanılabilecek yem bitkileri cinslerinden birisi de Fabaceae ailesinin bir üyesi olan fiğlerdir. Fabaceae familyası ülkemizde 69 cins 1145 takson ile ikinci en geniş familya konumundadır. Fiğ (Vicia) ise, bu aile içerisinde 89 takson ile üçüncü büyük cins olarak yer almaktadır (Kozan vd., 2013). Fiğ (Vicia spp.) yeşil-kuru ot, tane olarak üretimi, yeşil gübreleme materyali ile hayvanların otlatılması amacıyla değerlendirilen bir yem bitkisi materyalidir (Avc1 vd., 2002; Rubiales vd., 2013). Türkiye'de 2017 yılında fiğ ekilen alan miktarı 4456256 da iken 2018 yılında ekilen alanlarda daralma yaşanmasına karşın 2019 yılı itibariyle yeniden bir yükseliş (Tablo 1) gösterdiği görülmektedir. Bu durum yeşil ot olarak üretilen fiğ miktarına da doğrudan yansımış; üreticilerin hayvansal üretim için yem bitkilerine vermiş oldukları önemin de göstermektedir (Tenikecier vd., 2020).

Tablo 1

Ülkemizde fiğ ekilen alan ve üretim miktarları (TÜİK, 2021)

\begin{tabular}{ccc}
\hline Y1llar & Ekilen Alan (da) & Fiğ Üretimi $($ Yeşil ot $)(\mathrm{t})$ \\
\hline 2015 & 4365182 & 4281259 \\
2016 & 4428378 & 4542042 \\
2017 & 4456256 & 4597600 \\
2018 & 3869465 & 4273945 \\
2019 & 3914980 & 4303868 \\
\hline
\end{tabular}

Macar fiği (Vicia pannonica Crantz) ise, adını da aldığı Macaristan başta olmak üzere Orta Avrupa, Tuna ülkeleri ve Doğu Akdeniz Bölgesinde 20. yy başlarından itibaren kültürü yapılan sonrasında İspanya'dan Kafkaslara kadar geniş bir coğrafya da yetiştirilen bir yem bitkisidir (Gençkan, 1983; Leht ve Jaaska, 2002). Macar fiği, kuraklığa ve kış şartlarına dayanımı, yüksek rakımlı bölgelerde yetişebilme özelliği ile öne çıkmaktadır (Geçit vd., 2018; Aksoy ve Nursoy, 2010; Turan, 2019). Bunların yanında özellikle hayvansal üretim için önemli olan parametreler ile de ön plana çıkmaktadır. Ayrıca tahıllar ile karışık ekim ve yetişme olanağına sahip olması sebebiyle hayvanların beslenme kalitesini de artırdığı yapılan araştırmalar ile belirlenmiştir (Altınok ve Hakyemez, 2002; Büyükburç ve Karadağ, 2002; Turan, 2019).

Tüm bitkilerde olduğu gibi Macar fiğine ait genotiplere ait tohumlarda iklim, coğrafya ve toprak özelliklerine bağlı olarak değişim gösterebilmektedir (Dumanoğlu vd., 2021). Bitkisel üretimin temini oluşturan tohumların karakteristik özelliklerinin belirlenmesi ve bu değerler göz önüne alınarak uygun alet, makine ve sistemlerinin seçilmesi, tarımsal mekanizasyondan faydalanılarak ne az ürün kaybıyla üretim basamaklarının geçilebilmesi mümkün olmaktadır (Dumanoğlu vd., 2019). Ayrıca, sslah çalışmalarında genotip seçiminin yapılmasında, tohum özelliklerini iyileştirme yönelik yapılan çalışmalarda ve ürün işleme basamaklarında da tohum özelliklerinden faydalanılmaktadır.

$\mathrm{Bu}$ çalışmada, üreticiler tarafından tercih edilen on adet Macar fiğgi (Vicia pannonica Crantz) çeşidi tohumlarına ait karakteristik bazı fiziksel (şekil-boyut, yüzey alan, ortalama aritmetik ve geometrik çap, küresellik, bin tane ağırlığı) ve fizyolojik (çimlenme oranı, çimlenme zamanı, sürgün ve kök uzunlukları) özellikler belirlenmiştir. İncelenen bu özellikler tohumların kimlik verileri hakkında araştırmacılara bilgi 
vermesi, değerlendirme şeklilerinin belirlenebilmesi ve koşullara bağlı olarak bu özelliklerinin iyileştirmesi yolunda araştırmalara destek olması hedeflenmiştir.

\section{Materyal ve Yöntem}

$\mathrm{Bu}$ çalışma, Ege Üniversitesi ve Bingöl Üniversitesi Ziraat Fakültelerinde Tarım Makinaları ve Teknolojileri Bölümü ile Biyosistem Mühendisliği Bölümlerinde 2019-2020 yıllarında laboratuvar ortamında yürütülmüştür. Araştırmada kullanılan çeşitler Tablo 2'de verilmiştir. Çalışmada 10 farklı Macar fiği (Vicia pannonica Crantz) çeşidine ait tohumların bazı fiziksel ve fizyolojik özellikleri aşağıda belirtilen yöntemler izlenerek incelenmiştir.

Tablo 2

Araştırmada kullanılan Macar fiği çeşitleri

\begin{tabular}{cl}
\hline No & \multicolumn{1}{c}{ Macar fiği Çeşitleri } \\
\hline 1 & Aygün \\
2 & Akçalar \\
3 & Budak \\
4 & Enes \\
5 & Kansur \\
6 & Sarı efe \\
7 & Tarm Beyazı-98 \\
8 & Doğu Beyazı \\
9 & Anadolu Pembesi 2002 \\
10 & Oğuz 2002 \\
\hline
\end{tabular}

\subsection{Macar Fiği Tohumlarına Ait Bazı Fiziksel Özellikler}

Tohumların temel özelliklerinden biri olan şekil-boyut, uzunluk ( $\mathrm{mm})$, genişlik (mm) ve kalınlık (mm) değerleri hesaplanarak belirlenmektedir. Araştırmalardan elde edilen sonuçlara göre tohumların geometrik özellikleri (Tane genişliği/Tane uzunluğu) $(\mathrm{mm})$ (uzun $(0.6 \mathrm{~mm})$-orta $(0.6-0.7 \mathrm{~mm})-\mathrm{k} 1 \mathrm{sa}(>0.7 \mathrm{~mm})$ ) ve şekil özellikleri (uzunluk, genişlik, kalınlık $(\mathrm{mm})$ ) (yuvarlak $(\mathrm{a} \approx \mathrm{b} \approx \mathrm{c})$-oval $(\mathrm{a} / 3<\mathrm{b} \approx \mathrm{c})$-uzun $(\mathrm{c}<\mathrm{b}<\mathrm{a} / 3)$ ) belirlenerek ayrı ayrı incelenmektedir (Yağcığlu, 2015). Bu çalışmada, on adet Macar fiği çeşidine ait tohumlar rastgele örneklenmiş ve içlerinden 100'er adet tohum seçilerek bunlara ait uzunluk (mm), genişlik $(\mathrm{mm})$ ve yüzey alan $\left(\mathrm{mm}^{2}\right)$ değerleri kendine ait yazılımı (Image Focus 4.0 v2.4) olan stereo mikroskop (Nexius Zoom marka) ile belirlenmiştir (Dumanoğlu ve Geren, 2020).

Macar fiği tohumlarının şekil-boyut özelliklerine dair değerler belirlendikten sonra bu veriler kullanılarak tohumlara ait ortalama aritmetik çap $(\mathrm{mm})((D:(L+W) / 2))$, ortalama geometrik çap $(\mathrm{mm})\left(\left(D o:\left(L * D^{\wedge} 2\right)^{1} /\right.\right.$ 3)) değerleri ve küresellik ( $\Phi: D o / L)$ değerleri belirlenebilmektedir (L: Tohuma ait uzunluk değeri (mm); W: Tohuma ait genişlik değeri (mm)) (Mohsenin, 1970; Alayunt, 2000; Kara, 2012).

Tohumların bin dane ağırlıkları (g) da ayrıca önem taşımaktadır. Çalışma içerisinde incelenen on farklı Macar fiği çeşidine ait tohumlar rastgele (üçer tekrarlı) olacak şekilde sayılmış Radwag AS 220.R2 analitik terazide (0.0001 g hassasiyetine) tartım işlemi yapılarak bin tane ağırlı̆̆ı belirlenmiştir (Dumanoğlu vd., 2020). 


\subsection{Macar Fiği Tohumlarına Ait Bazı Fizyolojik Özellikler}

Çalışmada, on adet Macar fiği (Vicia pannonica Crantz) çeşidine ait tohumların çimlenme zamanı (gün) ve yüzdesi (\%) ile sürgün-kök uzunlukları $(\mathrm{cm})$ belirlenmiştir. Bunun için, her bir çeşitten rastgele alınan örnekler içerisinden seçilen tohumlar ISTA (2007) kurallarına göre 1 hafta ön soğutma işlemine $\left(+4^{\circ} \mathrm{C}\right.$ buzdolabında) tabii tutulmuştur. Bingöl Üniversitesi Ziraat Fakültesi laboratuvarlarında yer alan MEMMERT marka inkübatör içerisinde kontrollü şartlar altına $\left(20-25^{\circ} \mathrm{C}, \% 60\right.$ nem, karanlık ortam, 10 gün), dörder tekrarlı olacak şekilde petrilere ekim ve sayım işlemleri gerçekleştirilmiştir. Günlük olarak sayım işlemleri tamamlandıktan sonra her bir çeşit için rastgele olacak şekilde 100'er adet bitki seçilmiş ve bunların her birisinin sürgün-kök uzunlukları $(\mathrm{cm})$ ölçülmüştür. Ortalama çimlenme oranı $(\%): \sum \mathrm{n} / \mathrm{N} \mathrm{x100}$ (n: Çimlenen/çıkış yapan tohum sayısı; N: toplam tohum sayısı) (Duman ve Gökçöl, 2017); Ortalama çimlenme zamanı (gün): $\sum\left(\mathrm{g}_{\mathrm{x}} \mathrm{X} \mathrm{n}_{\mathrm{x}}\right) / \sum \mathrm{n}_{\mathrm{x}}$ ( $\mathrm{g}_{\mathrm{x}}$ : Çimlenme başlangıcındaki gün; $\mathrm{n}_{\mathrm{x}}$ : Sayımın yapıldığı gün çimlenen tohum sayısı; $\sum \mathrm{n}_{\mathrm{x}}$ : Toplam çimlenen tohum sayısı) şeklinde hesaplanmıştır (Akın ve Duman, 2018).

\section{3. İstatistiksel Analiz}

Bu çalışmada, Macar fiği (Vicia pannonica Crantz) tohumlarına ait bazı fiziksel ve fizyolojik özellikleri belirlenmeye çalışılmıştır. Tohumlar tesadüf parselleri deneme desenine göre incelenmiştir. Elde edilen veriler SPPSS V.22 programı ile önce One-Way ANOVA testi tohumların farklılığ $\mathrm{p}<0.05$ düzeyinde belirlenmiş daha sonra da bu değerlere TUKEY testi uygulanmıştır.

\section{Bulgular ve Tartışma}

\subsection{Macar Fiği Tohumlarına Ait Bazı Fiziksel Özellikler}

Bu çalışma içerisinde on farklı Macar fiğ (Vicia pannonica Crantz) çeşidine ait tohumlar incelenmiştir. Genel olarak tüm Macar fiği çeşitlerini birlikte değerlendirdiğimizde ortalama $4.034 \mathrm{~mm}$ uzunluk, $3.780 \mathrm{~mm}$ genişlik, $12.459 \mathrm{~mm}^{2}$ yüzey alanı, $3.907 \mathrm{~mm}$ aritmetik çap, $21.427 \mathrm{~mm}$ geometrik çap ve 5.158 küresellik değerine sahip olduğu belirlenmiştir. Elde edilen verilere göre Anadolu Pembesi 2002 ve Oğuz 2002 çeşitlerinin aynı grup içerisinde yer aldığı ve en yüksek ortalama uzunluk (sırasılyla $4.808 \mathrm{~mm}$ ve $4.804 \mathrm{~mm}$ ), genişlik (4.348 mm ve $4.413 \mathrm{~mm})$, yüzey alan $\left(17.007 \mathrm{~mm}^{2}\right.$ ve $\left.17.193 \mathrm{~mm}^{2}\right)$, aritmetik çap $(4.578 \mathrm{~mm}$ ve 4.608 $\mathrm{mm}$ ), geometrik çap ( $34.048 \mathrm{~mm}$ ve $34.503 \mathrm{~mm}$ ) ve küresellik (7.013 ve 7.108) değerlerine sahip oldukları belirlenmiştir. Budak çeşidi ise; ortalama uzunluk $(3.560 \mathrm{~mm})$, genişlik $(3.351 \mathrm{~mm})$, yüzey alanı $\left(9.615 \mathrm{~mm}^{2}\right)$, aritmetik çap $(3.456 \mathrm{~mm})$, geometrik çap $(14.487 \mathrm{~mm})$ ve küresellik $(4.011 \mathrm{~mm})$ değerleri açısından Macar fiği çeşitleri arasında en düşük değerlere sahip olduğu saptanmıştır. Elde edilen veriler, Gençkan (1983)'ın Macar fiğgi ile ilgili olarak vermiş olduğu bilgilerle (tohumlar yaklaşı $4 \mathrm{~mm}$ çapında, 2-2.5 mm uzunluğunda; kürevi ya da yassı formlarda; koyu esmer, siyah renge sahiptir) paralellik göstermektedir. Tüm Macar fiği çeşitlerinin uzunluk, genişlik değerleri incelendiğinde, tohumların kısa ve oval forma sahip olduğu saptanmıştır. Anadolu Pembesi 2002 ve Oğuz 2002 çeşitlerinin istatistiki olarak diğer çeşitlere göre özelliklerinin belirgin olduğu; Budak çeşidinin ise genel olarak diğer çeşitlerden istatistiki farklı grupta değerlendirildiği belirlenmiştir. Macar fiğlerinin ortalama $37.065 \mathrm{~g}$ bin dane ağırlığına sahip olduğu belirlenmiştir. Anadolu Pembesi 2002 (54.225 g) ve Oğuz 2002 (48.700 g) çeşitlerinin en ağır, Budak (26.925 g) ve Kansur (29.175 g) çeşitlerinin de en hafif bin dane ağırlığına sahip olduğu saptanmıştır (Tablo 3). Ülker ve Yüksel'in (2021) Uşak şartlarında yapmış oldukları çalışmada bazı Macar fiği çeşitlerinde (Budak, Kansur, Oğuz 2002, Sarıefe, Tarm Beyazı-98) elde ettikleri bin tane oranlarının (sırasıyla 32.24 g, 31.82 g, 30.39 g, $35.53 \mathrm{~g}$ ve $32.36 \mathrm{~g}$ ) bu araştırmada ölçülen değerler ile uyuştuğu belirlenmiştir. Seydoșoğlu'nun (2014) Diyarbakır ekolojik şartlarında bazı Macar fiğ genotipleri (Tarm Beyazı-98, Anadolu pembesi 2002, Budak, Oğuz 2002) ile yapmış olduğu çalışmada tohumların bin taneleri ile ilgili olarak elde etmiş olduğu değerler (sırasıyla 31g, 46.6g, 34.2g, 47.2g) ile bu araştırmada ölçülen değerlerin paralellik gösterdiği belirlenmiştir. 
Tablo 3

Macar fiği çeşitlerinin bazı fiziksel özellikleri

\begin{tabular}{|c|c|c|c|c|c|c|c|}
\hline \multirow[b]{2}{*}{ Çeşit Adı } & \multicolumn{7}{|c|}{ Tohum özellikleri } \\
\hline & $\begin{array}{l}\text { Uzunluk } \\
\text { (mm) }\end{array}$ & $\begin{array}{c}\text { Genişlik } \\
\text { (mm) }\end{array}$ & $\begin{array}{l}\text { Yüzey } \\
\text { alan } \\
\left(\mathrm{mm}^{2}\right)\end{array}$ & $\begin{array}{c}\text { Ort. } \\
\text { Aritmetik } \\
\text { Çap (mm) }\end{array}$ & $\begin{array}{c}\text { Ort. } \\
\text { Geometrik } \\
\text { Çap (mm) }\end{array}$ & Küresellik & $\begin{array}{l}\text { Bin Tane } \\
\text { Ağırlı̆ } 1 \\
\text { (g) }\end{array}$ \\
\hline Aygün & $3.780^{\mathrm{de}}$ & $3.589^{\mathrm{cd}}$ & $11.015^{\mathrm{bcd}}$ & $3.684^{\mathrm{de}}$ & $17.297^{\mathrm{de}}$ & $4.543^{\mathrm{de}}$ & 31.675 \\
\hline Akçalar & $3.889^{\mathrm{cd}}$ & $3.650^{\mathrm{cd}}$ & $11.545^{\mathrm{b}}$ & $3.769^{\mathrm{cd}}$ & $18.771^{\mathrm{de}}$ & $4.766^{\mathrm{cd}}$ & 35.500 \\
\hline $\begin{array}{l}\text { Anadolu Pembesi } \\
2002\end{array}$ & $4.808^{\mathrm{a}}$ & $4.348^{\mathrm{a}}$ & $17.007^{\mathrm{a}}$ & $4.578^{\mathrm{a}}$ & $34.048^{\mathrm{a}}$ & $7.013^{\mathrm{a}}$ & 54.225 \\
\hline Budak & $3.560^{\mathrm{f}}$ & $3.351^{\mathrm{e}}$ & $9.615^{\mathrm{d}}$ & $3.456^{\mathrm{f}}$ & $14.487^{\mathrm{f}}$ & $4.011^{\mathrm{f}}$ & 26.950 \\
\hline Doğu Beyazı & $3.899^{\mathrm{cd}}$ & $3.706^{c}$ & $11.660^{\mathrm{bcd}}$ & $3.802^{\text {cd }}$ & $19.029^{d}$ & $4.840^{\mathrm{cd}}$ & 33.325 \\
\hline Enes & $3.927^{\mathrm{c}}$ & $3.719^{b c}$ & $11.782^{\mathrm{bc}}$ & $3.823^{\mathrm{c}}$ & $19.405^{\mathrm{cd}}$ & $4.896^{\mathrm{c}}$ & 38.200 \\
\hline Kansur & $3.731^{\mathrm{e}}$ & $3.504^{\mathrm{d}}$ & $10.647^{\mathrm{cd}}$ & $3.618^{\mathrm{e}}$ & $16.573^{\mathrm{ef}}$ & $4.389^{\mathrm{e}}$ & 29.175 \\
\hline Oğuz 2002 & $4.804^{\mathrm{a}}$ & $4.413^{\mathrm{a}}$ & $17.193^{\mathrm{a}}$ & $4.608^{\mathrm{a}}$ & $34.503^{\mathrm{a}}$ & $7.108^{\mathrm{a}}$ & 48.700 \\
\hline Sar1efe & $3.878^{\mathrm{cd}}$ & $3.669^{\mathrm{c}}$ & $11.511^{\mathrm{bcd}}$ & $3.774^{\mathrm{cd}}$ & $18.695^{\text {de }}$ & $4.772^{\mathrm{cd}}$ & 35.675 \\
\hline Tarm Beyazı-98 & $4.068^{\mathrm{b}}$ & $3.847^{\mathrm{b}}$ & $12.613^{\mathrm{bc}}$ & $3.957^{\mathrm{b}}$ & $21.464^{\mathrm{b}}$ & $5.241^{\mathrm{b}}$ & 37.225 \\
\hline En az & 3.560 & 3.351 & 9.615 & 3.456 & 14.487 & 4.011 & 26.950 \\
\hline En çok & 4.808 & 4.413 & 17.193 & 4.608 & 34.503 & 7.108 & 54.225 \\
\hline Ortalama & 4.068 & 3.847 & 12.613 & 3.957 & 21.464 & 5.241 & 37.225 \\
\hline Stdv. & 0.428 & 0.344 & 2.569 & 0.385 & 7.019 & 1.055 & 8.453 \\
\hline $\begin{array}{l}\text { Varyasyon } \\
\text { Katsayis1 }\end{array}$ & 0.262 & 0.201 & 27.157 & 0.214 & 4.373 & 1.546 & 15.665 \\
\hline
\end{tabular}

\subsection{Macar Fiği Tohumlarına Ait Bazı Fizyolojik Özellikler}

Macar fiğlerinin (Vicia pannonica Crantz) çimlenme oranlarını incelediğimizde, bu çeşitler içerinde Kansur ve Tarım Beyazı-98 çeşitlerinin \%99 oranında çimlendiği en düşük çimlenme oranı ise \%88 oranında Enes ve \%89 oranı ile Akçalar çeşitlerinde elde edildiği belirlenmiştir. Anadolu Pembesi 2002 ve Oğuz 2002 çeşitlerinde hiç çıkış kayıt edilmemiştir. Ayrıca, çimlenme zamanı bakımından tohumlar birbirine yakın zamanlar içerisinde çimlenirken, en hızlı çimlenen Sarıefe çeşidi olurken, en yavaş çimlenen ise Enes çeşidi olmuştur (Tablo 4). Bağcı ve Mutlu (2014) yapmış oldukları çalışmada, Anadolu pembesi 2002, Oğuz 2002, Tarım Beyazı-98 Macar fiği çeşitlerini incelemişler ve elde etikleri sonuçlara göre tohumların çimlenme oranlarını sırasıyla \%93.33, \%83.33 ve \%\%95 olarak belirlemişlerdir. Avcı (2019), yapmış olduğu çalışmada incelediği altı farklı Macar fiğinden dördü bu çalışma içerisinde incelenen Budak, Kansur, Tarm Beyazı-98 ve Anadolu Pembesi 2002'dir. Bu tohumlara ait çimlenme oranları ve süreleri sırasılla \%95 ile 1.97 gün, \%98.50 ile 1.99 gün, $\% 98.50$ ile 1.91 gün ve $\% 99.50$ ile 2.79 gün şeklinde olmuştur. 
Tablo 4

Macar fiği çeşitlerinin çimlenme oranı ve zamanı

\begin{tabular}{lcc}
\hline \multicolumn{1}{c}{ Çeşit adı } & Çimlenme Oran $(\%)$ & Çimlenme zaman1 (gün) \\
\hline Aygün & 95 & 1.457 \\
Akçalar & 89 & 1.523 \\
Budak & 91 & 1.480 \\
Enes & 88 & 1.631 \\
Kansur & 99 & 1.487 \\
Sarı efe & 93 & 1.448 \\
Tarm Beyazı-98 & 99 & 1.483 \\
Doğu Beyazı & 91 & 1.587 \\
\hline Anadolu pembesi 2002 & 0 & 0 \\
Oğuz 2002 & 0 & 0 \\
\hline
\end{tabular}

Macar fiğgi çeşitlerinin ortalama sürgün $(\mathrm{cm})$ ve kök $(\mathrm{cm})$ uzunlukları Tablo 5'de verilmiştir. Anadolu Pembesi 2002 ve Oğuz 2002 çeşitlerine ait tohumlarda çıkış olmadığı için ortalama sürgün ve kök uzunluklarına bu çeşitler dahil edilmemiştir. Bunların dışında kalan 8 çeşitten 100'er adet örnekleme yapılmıştır. Yapılan ölçüm sonrasında, en yüksek sürgün Kansur çeşidinde (10.227), kök uzunluğu ise Akçalar çeşidinde $(6.661 \mathrm{~cm})$ ölçülmüştür. Tüm Macar fiğlerinin genel olarak ortalama sürgün uzunluğu $8.771 \mathrm{~cm}$, kök uzunluğu ise 5.663 cm olarak ölçülmüştür (Tablo 5). Genel olarak birbirine yakın sürgün ve kök uzunlukları elde edilmiştir. Avc1 (2019) çalışmasında incelediği Macar fiğlerine (Budak, Kansur, Tarm Beyazı-98 ve Anadolu Pembesi 2002) ait sürgün-kök uzunluklarını sırasıyla $5.85 \mathrm{~cm}$ ve $4.62 \mathrm{~cm}, 5.65 \mathrm{~cm}$ ve $4.15 \mathrm{~cm}, 6.85 \mathrm{~cm}$ ve $3.85 \mathrm{~cm}, 4.87 \mathrm{~cm}$ ve $4.05 \mathrm{~cm}$ olarak ölçmüştür.

Tablo 5

Macar fiğgi çeşitlerinin ortalama sürün ve kök uzunlukları

\begin{tabular}{lcc}
\hline \multicolumn{1}{c}{ Çeşit ad1 } & Ortalama Sürgün uzunluğu $(\mathrm{cm})$ & Ortalama Kök uzunluğu $(\mathrm{cm})$ \\
\hline Aygün & 9.667 & 5.667 \\
Akçalar & 10.223 & 6.661 \\
Budak & 8.165 & 6.483 \\
Enes & 9.471 & 5.188 \\
Kansur & 10.227 & 6.307 \\
Sar1 efe & 10.079 & 6.341 \\
Tarm Beyazı-98 & 6.722 & 4.467 \\
Doğu Beyazı & 5.613 & 4.191 \\
Anadolu Pembesi 2002 & 0 & 0 \\
Oğuz 2002 & 0 & 0 \\
\hline Ortalama & 8.771 & 5.663 \\
\hline
\end{tabular}

\section{Sonuçlar}

Bu çalışmada, on adet Macar fiği (Vicia pannonica Crantz) çeşidine ait tohumların bazı fiziksel (ve fizyolojik özellikleri incelenmiştir. İncelenen fiziksel özelliklerden uzunluk, genişlik, yüzey alanı, aritmetik çap, geometrik çap ve küresellik açısından Anadolu Pembesi 2002 ve Oğuz 2002 çeşitlerinin ön plana çıktığı belirlenmiş; fizyolojik özelliklerden bakımından ise, çimlenme oranı açısından Kansur ve Tarm Beyazı 98, çimlenme süresi açısından Sarıefe, sürgün uzunluğu açısından Akçalar ve Kansur, kök uzunluğu açısından ise Akçalar çeşidinin üstün özellikler gösterdiği tespit edilmiştir. Bu veriler, başta 1slah ve tohum teknolojisi çalışmaları olmak üzere ekimden hasada kadar geçen bitkisel üretim aşamalarında tarımsal mekanizasyon yardımı ile yapılacak olan işlemlerde ürün kayıplarının en aza indirmesi ve uygun alet, makine sistemlerin belirlenmesi amacıyla değerlendirileceği öngörülmektedir. 


\section{Yazar Katkıları}

Zeynep Dumanoğlu: Analiz ve makale yazmıştır.

Erdal Çaçan: Tohumların temini ve makale yazmıştır.

Kağan Kökten: Tohumların temini ve makale yazmıştır.

\section{Çıkar Çatışması}

Yazarlar çıkar çatışması bildirmemişlerdir.

\section{Kaynaklar}

Alayunt, F.N. (2000). Biyolojik Malzeme Bilgisi, Ege Üniversitesi Ziraat Fakültesi Tarım Makineleri Bölümü Ders Kitabı, Ege Üniv. Ziraat Fak. Yayınları No: 541.

Akın, N. ve Duman, İ. (2018). Tütün (Nicatiana tabacum L.) Tohumlarının Çimlenme Özelliklerinin İyileştirilmesi. Ege Üniversitesi Ziraat Fakültesi Dergisi, 55(3), 327-334. Erişim adresi: https://dergipark.org.tr/tr/download/article-file/544201

Aksoy, İ. ve Nursoy, H. (2010). Vejetasyonun farklı dönemlerinde biçilen Macar fiği Buğday karışımın besin madde kompozisyonu, rumende yıkılım özellikleri, in vitro sindirilebilirlik ve rölatif yem değerlerinin belirlenmesi. Kafkas Üniversitesi Veterinerlik Fakülte Dergisi, 16(6), 925-931. Erişim adresi: https://vetdergikafkas.org/uploads/pdf/pdf_KVFD_811.pdf

Avc1, M., Meyveci, K., Karakurt, E., Karaçam, M., Sürek, D., Özdemir, B. ve Yürürer A.Ş. (2002). Macar fiği (Vicia pannonica L. cv. Tarımbeyazı-98) ile tüylü fiğ (Vicia villosa L. cv. Munzur-98) çeşitlerinin tohumluk üretiminde değişik ekim sıklıklarının etkinliğinin araştırılması. Tarla Bitkileri Merkez Araştırma Enstitüsü Dergisi, 12(1-2), 14-29.

Avcı, S. (2019). Macar fiği çeşitlerinde tuzluluğun çimlenme ve fide büyümesi üzerine etkileri. $4^{\text {th }}$ International Anatolian Agriculture, Food, Enviroment and Biology Congres (TARGID). Ed: A.Şekercioğlu, H.Eleroğlu ve M. Duman. p:555-564, Afyonkarahisar. Erişim adresi: https://www.researchgate.net/profile/TohfaNasibova/publication/338955265_Full_Book_-

4th International Anatolian Agriculture Food Environment and Biology Congress April 2019 Afyon karahisar_Turkey/links/5e34842792851c7f7f11aab2/Full-Book-4th-International-Anatolian-AgricultureFood-Environment-and-Biology-Congress-April-2019-Afyonkarahisar-Turkey.pdf\#page=574

Altınok. S. ve Hakyemez, H.B. (2002). Ankara koşullarında tüylü fiğ ve koca fiğgin arpa ile karışımlarında farklı karışım oranlarının yem verimlerine etkileri. Ankara Üniversitesi Tarım Bilimleri Dergisi, 8, 5-50.

Bağcı, M. ve Mutlu, H. (2014). Üç Macar Fiği (Vicia pannonica Crantz.) Çeşidinde Farklı Dozlarda Gama Işını Uygulamasının M1 Generasyonunda Bazı Bitkisel Özellikleri Üzerine Etkileri. Tarla Bitkileri Merkez Araştırma Enstitü Dergisi, 23(1), 31-40. Erişim adresi: https://dergipark.org.tr/en/download/articlefile/118560

Büyükburç, U. ve Karadağ, Y. (2002). The amount of $\mathrm{NO}_{3}-\mathrm{N}$ transfered to soil by legumes, forage ve seed yield, and the forage qulityof annual legume+triticale mixtures. Turk Agric. For, 26, 281-288. Erişim adresi: https://journals.tubitak.gov.tr/agriculture/issues/tar-02-26-5/tar-26-5-7-0201-1.pdf

Duman, İ. ve Gökçöl, A. (2017). Biber (Capsicum annuum L.) ve Patlıcan (Solanum melongena L.) Tohumlarının Fidelik Performanslarının İyileştirilmesi. Ege Üniversitesi Ziraat Fakültesi Dergisi, 54(3), 333-340. Erişim adresi: https://dergipark.org.tr/en/download/article-file/416432

Dumanoğlu, Z., Çaçan, E. ve Kökten, K. (2021). Korunga (Onobrychis viciifolia Scop.) Genotiplerine Ait Tohumların Fiziksel Özelliklerinin Belirlenmesi. Journal of Anatolian Environmentaland Animal Sciences, 6(1), 18-24. Erişim adresi: https://dergipark.org.tr/en/download/article-file/1319526

Dumanoğlu, Z., Dönmez, C. ve Çakır, M.F. (2020). General Characteristics of Seeds of Some Anise (Pimpinella anisum L.) Lines and Effects of Film Coating on These Seeds. Turkish Journal of Agriculture - Food Science and Technology (TURJAF), 8(1), 46-53. Erişim adresi: http://www.agrifoodscience.com/index.php/TURJAF/article/view/2660/1483 
Dumanoğlu, Z. ve Geren, H. (2020). An Investigation on Determination of Seed Characteristics of Some GlutenFree Crops (Amarantus mantegazzianus, Chenopodium quinoa Willd., Eragrostis tef [Zucc] Trotter, Salvia hispanica L.). Turkısh Journal of Agriculture-Food Science and Technology, 8(8), 1650-1655. Erişim adresi: http://www.agrifoodscience.org/index.php/TURJAF/article/view/3394/1722

Dumanoğlu, Z., Ozkan, S.S. ve Topcu, G.D. (2019). İtalyan çimi (Lolium multiflorum L.) çeşitlerine ait tohumların bazı fiziksel özelliklerinin belirlenmesi. Uluslararası Tarım ve Yaban Hayatı Bilimleri Dergisi, 5(2), 292-298. Erişim adresi: https://dergipark.org.tr/en/download/article-file/881224

Geçit, H.H., Çiftçi, C.Y., Emeklier, H.Y., İkincikarakaya, S.Ü., Adak, M.S., Kolsarıcı, Ö., Ekiz, H., Altınok, S., Sancak, C., Sevimay C.S. ve Kendir H. (2018). Tarla Bitkileri. Ankara Üniversitesi Ziraat Fakültesi Yayınlarl. Yayın No: 1643, Ankara.

Gençkan, S.M. (1983). Yem Bitkileri Tarımı. Ege Üniversitesi Yayınları. Yayın No: 467, İzmir.

ISTA (2007). International Rules for Seed Testing, International Rules for Seed Testing Book.

Kara, M. (2012). Biyolojik Ürünlerin Fiziksel Özellikleri, Atatürk Üniv. Ziraat Fakültesi Yayınları No: 242.

Kozan, E., Anul, S.A. ve Tatl1, I.I. (2013). In vitro anthelmintic effect of Vicia pannonica var. purpurascenson trichostrongylosis in sheep. Experimentl Prasitology, 134, 299-303. https://doi.org/10.1016/j.exppara.2013.03.018

Leht, M. ve Jaaska, V. (2002). Cladistic and phenetic analysis of relationships in Vicia subgenus Vicia (Fabacea) by morphology and isozymes. Plant System Evol, 232, 237-260. https://doi.org/10.1007/s006060200045

Mohsenin, N.N. (1970). Physical Properties of Plant and Animal Materials. Gordon and Breach Science Publishers.

Rubiales, D., Sillero J.C. ve Emeran, A.A. (2013). Response of vetches (Vicia spp.) to speciallized froms Uramuces vicia-fabae and to Uromyces pisi. Crop Production, 46, 38-43. https://doi.org/10.1016/j.cropro.2012.12.011

Seydosoğlu, S. (2014). Diyarbakır ekolojik koşullarında bazı Macar fiği genotiplerinin verim ve verim unsurlarının belirlenmesi. Türk Doğa ve Fen Dergisi, 3(1), 49-54. Erişim adresi: https://dergipark.org.tr/tr/download/article-file/199052

Tenikecier, H.S., Orak, A., Tekeli, A.S. ve Gültekin B. (2020). Bazı Macar fiği (Vicia pannonica Crantz.) genotipelerinde farklı biçim zamanlarının ot verimi ve bazı kalite özelliklerine etkisi. Türk Tarım ve Doğa Bilimleri Dergisi, 7(4), 833-847. Erişim adresi: https://dergipark.org.tr/en/download/article-file/1246490

Turan, N. (2019). Macar fiği ile arpa yaş otunun farklı oranlarda karıştırılarak elde edilen silajın kimyasal kompozisyonu ve kalite parametrelerinin belirlenmesi. Avrupa Bilim ve Teknoloji Dergisi, 17, 787-793. Erişim adresi: https://dergipark.org.tr/en/download/article-file/859525

TÜIK (2019). Türkiye İstatistik Kurumu, Bitkisel Üretim İstatistikleri.

TÜIK (2021). Türkiye İstatistik Kurumu, Bitkisel Üretim İstatistikleri.

Ülker, E., ve Yüksel, O. (2021). Uşak şartlarında bazı Macar fiği (Vicia pannonica Crantz.) çeşitlerinin verim ve tarımsal özelliklerinin belirlenmesi. Isparta Uygulamalı Bilimler Üniversitesi Ziraat Fakültesi Dergisi, 16(1), 52-58. Erişim adresi: https://dergipark.org.tr/en/download/article-file/1747254

Yağcıŏlu, A. (2015). Ürün İşleme, Ege Üniversitesi Yayınları Ziraat Fakültesi Yayın No: 517, Genişletilmiş 2. Bask1. 